\title{
Observational Study of the Effect of the Hydroxychloroquine/Azithromycin Combination in Patients Hospitalized for a Severe Form of COVID-19
}

\begin{abstract}
Santucci Raoul ${ }^{1}$, Vinzio Stéphane ${ }^{2}$, Brisson Jihane ${ }^{3}$, Caille Cécile ${ }^{4}$, Geiger Audrey $^{5}$, Merheb Gabriel$^{5}$, Gibert Stéphanie ${ }^{6}$, Mattelaer Xavier $^{7}$, Faller Anne-Laure ${ }^{8}$, Muller Clotilde ${ }^{8}$, Denis Julien ${ }^{9}$, Cevallos Ramiro ${ }^{4}$, Bouayad-Agha Karim ${ }^{10}$, Couturier Franck ${ }^{1}$, ChallanBelval Patrice ${ }^{4}$, Martinez Valérie ${ }^{11}$, Maloisel Frédéric ${ }^{12 *}$

${ }^{1}$ Service Pharmacie-Stérilisation, Groupe Hospitalier Saint Vincent, Clinique Sainte Anne, Rue Philippe Thys, 67000 Strasbourg, France ${ }^{2}$ Service de Médecine Interne, Groupe Hospitalier Mutualiste de Grenoble, 8 Rue Dr Calmette, 38000 Grenoble, France

${ }^{3}$ Service d'Hygiène Hospitalière, Groupe Hospitalier Saint Vincent, Clinique Sainte Barbe, 29 rue du Faubourg National, 67000 Strasbourg, France ${ }^{4}$ Service de Médecine Interne, Groupe Hospitalier Saint Vincent, Clinique Sainte Anne, Rue Philippe Thys, 67000 Strasbourg, France ${ }^{5}$ Service de Réanimation, Groupe Hospitalier Saint Vincent, Clinique Sainte Anne, Rue Philippe Thys, 67000 Strasbourg, France ${ }^{6}$ Service de Réanimation, Groupe Hospitalier Saint Vincent, Clinique Sainte Barbe, 29 rue du Faubourg National, 67000 Strasbourg, France 7Service d'Unité de Soins Palliatifs, Groupe Hospitalier Saint Vincent, Clinique de la Toussaint, 11 Rue de la Toussaint, 67000 Strasbourg, France ${ }^{8}$ Service de Néphrologie, Groupe Hospitalier Saint Vincent, Clinique Sainte Anne, Rue Philippe Thys, 67000 Strasbourg, France ${ }^{9}$ Service de Médecine-Chirurgie, Groupe Hospitalier Saint Vincent, Clinique Saint Luc, 10 Rue des Forges, 67130 Schirmeck, France ${ }^{10}$ Service des Urgences, Groupe Hospitalier Saint Vincent, Clinique Sainte Anne, Rue Philippe Thys, 67000 Strasbourg, France ${ }^{11}$ Service de Gériatrie, Groupe Hospitalier Saint Vincent, Clinique Sainte Barbe, 29 rue du Faubourg National, 67000 Strasbourg, France ${ }^{12}$ Service d'Onco-Hématologie - Strasbourg Oncologie Libérale, Groupe Hospitalier Saint Vincent, Clinique Sainte Anne, Rue Philippe Thys, 67000 Strasbourg, France
\end{abstract}

${ }^{*}$ Corresponding author: Dr. Maloisel Frédéric, MD, PhD, Strasbourg Oncologie Libérale, Groupe Hospitalier Saint Vincent, Clinique Sainte Anne, Rue Philippe Thys, 67000 Strasbourg, France; E-mail: FMALOISEL@solcrr.org

Received: July 30, 2020; Accepted: August 10, 2020; Published: August 17, 2020

\begin{abstract}
Following the demonstration in vitro of the efficiency of a synergistic effect of hydroxychloroquine (HCQ) associated with azithromycin (AZI) against the SARS-CoV-2, some studies have aimed to evaluate its efficiency in a clinical setting. We present the results of a non-randomized observational study of patients admitted for a severe form of COVID-19 disease who have been treated by HCQ/AZI after collegial physicians' decision. Of the 306 patients included (average age: 72.8 years), 53 received the HCQ/AZI association. Univariate analysis shows in non-survivors a higher average age, more severe clinical signs on admission (lung invasion rate $>50 \%$, Dyspnea and creatinine $>133 \mu \mathrm{mol} / \mathrm{L}$ ) and more comorbidities (cerebrovascular accident, chronic kidney disease, immunodeficiency). We evaluated the efficiency of the HCQ/AZI treatment on a population ( $\mathrm{n}=96)$ with comparable characteristics (age, risk factor, gravity...). If mortality of the patients treated with HCQ/AZI seems different in this sub-study population (HCQ/AZI: $0 \%$ vs. Other: $8 \%$ ), the methods of the study and its size do not allow the identification of a statistically significant difference $(\mathrm{p}=0.122)$.
\end{abstract}

At this time of the epidemic, the HCQ/AZI must be evaluated in a randomized trial at the right and safe dosage.

What is Already Known about This Subject?

The discussion on the efficiency of the hydroxychloroquine/azithromycin combination remains open. To date, no randomized trial has demonstrated the efficiency of this combination in patients with a severe form of COVID-19.

What This Study Adds?

We report the results of a non-randomized observational study compared hydroxychloroquine/azithromycin combination to any antiviral treatment for patients with a severe form of COVID-19. We warn of the difficulty of interpreting these results in the absence of randomization. 


\section{Introduction}

At the end of 2019, a new coronavirus, designated SARS-CoV-2, was causing an epidemic of respiratory diseases in China. The city of Wuhan (China) went into full confinement on January 23, $2020^{1}$. On March 12, 2020, the World Health Organization (WHO) declared the COVID-19 pandemic. The importance of the number of symptomatic patients and the particular gravity of some of them lead the Hospitals to reorganize in emergencies on an almost daily basis both at the structural, organizational and medical level. Among the antiviral treatments likely to be effective on the symptoms of SARS-CoV-2, three molecules or associations stood out: remdesivir, the fixed combination ritonavir/lopinavir and (hydroxy) chloroquine associated or not with azithromycin [1].

In mid-March, remdesivir and the ritonavir/lopinavir combination were announced as a complete disruption by the laboratories producing them. The French Ministry of Health then supervised the off-label use of hydroxychloroquine, conditioning it to severity criteria and subject to a collegial decision by the medical profession. We present the results of a monocentric, observational, retrospective study aimed at evaluating the efficiency of the hydroxychloroquine/ azithromycin combination on the COVID-19 disease.

\section{Methods}

All patientshospitalized at our center for a severe form ofCOVID-19 disease were included in the study. The diagnosis of COVID-19 disease combined the recording of symptoms (fever, caugh, fatigue, myalgia, headache, dyspnea, diarrhea, nausea, vomiting, anorexia, anosmia, aguesia, dizziness, fall, hypoxemia) with a SARS-CoV-2 reversetranscriptase-polymerase-chain-reaction (RT-PCR) and/or standard low dose CT imaging. The following characteristics were sought in the study population: age, body mass index (BMI), active or history of smoking, chronic kidney/heart/respiratory disease, hypertension, diabetes mellitus, dyslipidemia, cerebrovascular accident and immunodeficiency (including cancer under treatment). The home drugs treatment of interest were sought: angiotensin-convertingenzyme (ACE) inhibitors and angiotensin-receptor blockers (ARBs) calcium-chanel inhibitor, diuretics, betablockers, corticosteroids and aspirin. We have listed antivirals under evaluation: remdesivir, hydroxychloroquine (HCQ), azithromycin (AZI), ritonavir/lopinavir. The severity of the COVID-19 stage of the patients included was assessed on the basis of at least one of the following criteria: dyspnea, $\mathrm{O} 2$ saturation $\leq 93 \%$, radiological pulmonary infiltrates $>50 \%$ at $24-48$ hours of admission [2].

\section{HCQ/AZI}

The dosage of HCQ/AZI was: HCQ (D1-D10; 600mg per day in 3 doses) combined with azithromycin (D1: 500mg in 1 dose; D2-D5: $250 \mathrm{mg}$ per day). Only patients not on dialysis, with no contraindication to HCQ/AZI treatment (e.g. severe kidney failure, widening of the QTc wave) received treatment with HCQ/AZI after collegial physician decision. All patients on HCQ/AZI underwent an electrocardiogram before initiating treatment. Once treatment was started, an electrocardiogram was performed daily during hospitalization, as well as a determination of serum potassium, magnesemia and blood sugar. In order to reduce the biases linked to the care of patients, to the comorbidities, to the typology of the medical service (e.g. palliative care, geriatry) and to the contraindication of HCQ/AZI treatment (dialysis), we have make a sub-study. In this sub-study only patients treated in internal medicine were included and we have excluding dialysis patients.

\section{Clinical Outcomes}

Critical disease defined by death or transfer to intensive care unit (ICU) and death alone were the two main outcomes.

\section{Statistical Analysis}

Continuous data are summarized as mean (standard deviation) and categorical data as frequency (percentage). For univariate comparisons $\mathrm{T}$-test and $\mathrm{Chi}-2$ tests were used as appropriate to compare differences between non-critical and critical disease or survivor and non-survivor. The multivariate analysis used logistic regression ajusted on age, sex, body mass index (BMI), chronic heart disease, hypertension, diabetes mellitus, chronic kidney disease, hemodialysis, chronic lung disease (asthma or chronic obstructive lung disease), personal history of stroke, current or former tobacco use, treatment with immunosuppressive drugs (including anticancer drugs), creatine and C-reactive protein (CRP) levels, percentage of lung affected on CT-scan, low oxygen saturation, dyspnea, oxygen flow. A two-sided $\mathrm{p}$ value $<0.05$ was considered statistically significant. Statistical analyses were performed with SPSS 26.0 package. Neither patients nor the public were involved in the conception or conduct of the study.

\section{Results}

Between March 15 and April 15, 2020, 314 patients were admitted into the different wards. Eight patients were transferred to another hospital and were considered loss of follow-up: 6 were transferred to another region to vacant intensive care beds and 2 were taken care of for extracorporeal membrane oxygenation. The median age was 75.6 \pm 14.5 years. The number of days between the onset of symptoms and hospitalization was $6.6 \pm 7.8$ days. Men were a little more represented (54\%).

\section{Comorbidities}

Table 1 shows major comorbidities recorded on admission. The most common were chronic heart disease (71\%), hypertension (58\%), dyslipidemia (36\%), chronic kidney disease (27\%), diabetes mellitus (26\%), immunodeficiency $(21 \%)$ and chronic respiratory disease (19\%). Eighty nine percent of the patients have comorbidity with an average number of comorbidities of $4.1 \pm 2.3$. Three per cent $(8 / 306)$ of patients were current smokers and $10 \%$ were former smokers. It can be noted that $26 \%$ of patients have a BMI $>30 \mathrm{~kg} / \mathrm{m}^{2}$.

\section{Home Drug Treatments}

Home drug treatments included beta-blockers (31\%), aspirin (30\%), diuretics (27\%), calcium channel blockers (23\%), ARBs (22\%), ACE inhibitors (20\%) and corticosteroids (5\%). No patient was treated by non-steroidal anti-inflammatory drugs (Table 1). 
Maloisel Frédéric (2020) Observational Study of the Effect of the Hydroxychloroquine/Azithromycin Combination in Patients Hospitalized for a Severe Form of COVID-19

Table 1: Demographic findings of patients on admission.

\begin{tabular}{|c|c|c|c|c|}
\hline Demographic data & $\begin{array}{c}\text { Total } \\
(\mathrm{N}=306)\end{array}$ & $\begin{array}{l}\text { Survivor } \\
(\mathrm{N}=231)\end{array}$ & \begin{tabular}{|c|}
$\begin{array}{c}\text { Non-survivor } \\
(\mathrm{N}=75)\end{array}$ \\
\end{tabular} & p-value ${ }^{*}$ \\
\hline Age - yr & $75.6 \pm 14.5$ & $72.8 \pm 14.7$ & $84.0 \pm 9.9$ & $<0.0001$ \\
\hline Sex (male sex) & $54 \%$ & $55 \%$ & $49 \%$ & 0.394 \\
\hline Weight (kg) & $74.8 \pm 15.8$ & $76.3 \pm 15.7$ & $70.2 \pm 15.4$ & 0.007 \\
\hline Body mass index $\left(\mathrm{kg} / \mathrm{m}^{2}\right)$ & $26.8 \pm 5.0$ & $27.2 \pm 5.0$ & $25.6 \pm 4.9$ & 0.03 \\
\hline $\mathrm{BMI}<25 \mathrm{~kg} / \mathrm{m}^{2}(\%)$ & $59 \%$ & $61 \%$ & $50 \%$ & 0.11 \\
\hline BMI $25-29.9 \mathrm{~kg} / \mathrm{m}^{2}(\%)$ & $32 \%$ & $34 \%$ & $28 \%$ & 0.396 \\
\hline $\mathrm{BMI} \geq 30 \mathrm{~kg} / \mathrm{m}^{2}(\%)$ & $26 \%$ & $27 \%$ & $22 \%$ & 0.376 \\
\hline Nursing home resident (\%) & $13 \%$ & $10 \%$ & $23 \%$ & 0.003 \\
\hline \multicolumn{5}{|l|}{ Severity and mortality } \\
\hline Death (\%) & $25 \%$ & $0 \%$ & $100 \%$ & - \\
\hline ICU transfer (\%) & $3 \%$ & $3 \%$ & $3 \%$ & 0.871 \\
\hline $\begin{array}{l}\text { Critical cases (Death or transfer to } \\
\text { ICU) (\%) }\end{array}$ & $27 \%$ & $3 \%$ & $100 \%$ & $<0.0001$ \\
\hline $\begin{array}{l}\text { Time from symptom onset to } \\
\text { admission (days) }\end{array}$ & $6.6 \pm 7.8$ & $7.2 \pm 7.5$ & $4.5 \pm 8.5$ & 0.013 \\
\hline Length of stay in hospital (days) & $11.3 \pm 10.0$ & $12.2 \pm 9.4$ & $8.5 \pm 11.3$ & 0.005 \\
\hline $\begin{array}{l}\text { Time between admission and ICU } \\
\text { transfer (days) }\end{array}$ & $1.1 \pm 1.7$ & $1.2 \pm 1.7$ & $1.0 \pm 1.9$ & 0.802 \\
\hline \multicolumn{5}{|l|}{ Comorbidities (\%) } \\
\hline Hypertension & $58 \%$ & $55 \%$ & $67 \%$ & 0.065 \\
\hline Diabetes mellitus & $26 \%$ & $27 \%$ & $25 \%$ & 0.797 \\
\hline Chronic heart disease & $71 \%$ & $67 \%$ & $84 \%$ & 0.005 \\
\hline Dyslipemia & $36 \%$ & $33 \%$ & $44 \%$ & 0.094 \\
\hline Chronic respiratory disease & $19 \%$ & $20 \%$ & $15 \%$ & 0.276 \\
\hline Chronic kidney disease & $27 \%$ & $23 \%$ & $43 \%$ & 0.001 \\
\hline Dialysis & $4 \%$ & $3 \%$ & $7 \%$ & 0.232 \\
\hline Immunodeficiency & $21 \%$ & $16 \%$ & $36 \%$ & $<0.0001$ \\
\hline Cerebrovascular accident & $20 \%$ & $16 \%$ & $32 \%$ & 0.002 \\
\hline At least one comorbidity & $89 \%$ & $87 \%$ & $97 \%$ & 0.009 \\
\hline \multicolumn{5}{|l|}{ Smoking status (\%) } \\
\hline Current smoker & $3 \%$ & $3 \%$ & $1 \%$ & 0.424 \\
\hline Former smoker & $10 \%$ & $9 \%$ & $15 \%$ & 0.134 \\
\hline \multicolumn{5}{|l|}{ Home drug treatments (\%) } \\
\hline ACE inhibitors & $20 \%$ & $19 \%$ & $24 \%$ & 0.31 \\
\hline ARBs & $22 \%$ & $22 \%$ & $21 \%$ & 0.955 \\
\hline Calcium-chanel inhibitor & $23 \%$ & $22 \%$ & $24 \%$ & 0.729 \\
\hline Diuretics & $27 \%$ & $22 \%$ & $44 \%$ & $<0.0001$ \\
\hline Betablockers & $31 \%$ & $27 \%$ & $44 \%$ & 0.007 \\
\hline Corticosteroids & $5 \%$ & $3 \%$ & $11 \%$ & 0.008 \\
\hline Aspirin & $30 \%$ & $25 \%$ & $45 \%$ & 0.001 \\
\hline
\end{tabular}

${ }^{*}$ p-value univariate statistical test between Survivor VS Non-Survivor. - : statistical test non applicable.

\section{Severity of the Clinical Case}

At the admission, $43 \%$ of the patients presented a C-reactive protein $>100 \mathrm{mg} / \mathrm{L}, 43 \%$ an oxygen saturation $\leq 93 \%, 21 \%$ a creatinine $>133 \mu \mathrm{mol} / \mathrm{L}$ and $7 \%$ of the patient presented a proportion of lung
Table 2: Clinical, laboratory and radiographic findings of patients on admission.

\begin{tabular}{|c|c|c|c|c|}
\hline Symptoms at onset of illness (\%) & $\begin{array}{c}\text { Total } \\
(\mathrm{N}=306)\end{array}$ & $\begin{array}{l}\text { Survivor } \\
(\mathrm{N}=231)\end{array}$ & $\begin{array}{c}\text { Non-survivor } \\
(\mathrm{N}=75)\end{array}$ & p-value ${ }^{*}$ \\
\hline Fever & $60 \%$ & $62 \%$ & $55 \%$ & 0.266 \\
\hline Cough & $51 \%$ & $52 \%$ & $51 \%$ & 0.898 \\
\hline Fatigue & $59 \%$ & $58 \%$ & $60 \%$ & 0.812 \\
\hline Myalgia & $18 \%$ & $20 \%$ & $11 \%$ & 0.058 \\
\hline Headache & $8 \%$ & $9 \%$ & $4 \%)$ & 0.184 \\
\hline Dyspnea & $67 \%$ & $64 \%$ & $77 \%$ & 0.028 \\
\hline Diarrhea & $30 \%$ & $33 \%$ & $21 \%$ & 0.058 \\
\hline Nausea or vomiting & $9 \%$ & $11 \%$ & $1 \%$ & 0.008 \\
\hline Anorexia & $11 \%$ & $12 \%$ & $11 \%$ & 0.809 \\
\hline Anosmia or ageusia & $6 \%$ & $7 \%$ & $1 \%$ & 0.054 \\
\hline Dizziness. fall & $17 \%$ & $16 \%$ & $19 \%$ & 0.657 \\
\hline Hypoxemia (oxygen saturation $<93 \%$ ) & $43 \%$ & $40 \%$ & $55 \%$ & 0.024 \\
\hline \multicolumn{5}{|l|}{ Inpatient drug treatments $(\%)$} \\
\hline Hydroxychloroquine with azithromycin & $17 \%$ & $22 \%$ & $4 \%$ & $<0.0001$ \\
\hline Hydroxychloroquine alone & $2 \%$ & $1 \%$ & $3 \%$ & 0.417 \\
\hline Azithromycin alone & $4 \%$ & $5 \%$ & $1 \%$ & 0.184 \\
\hline Lopinavir with Ritonavir & $4 \%$ & $4 \%$ & $5 \%$ & 0.593 \\
\hline Oxygen therapy & $87 \%$ & $86 \%$ & $91 \%$ & 0.269 \\
\hline Invasive ventilation & $9 \%$ & $9 \%$ & $9 \%$ & 0.858 \\
\hline \multicolumn{5}{|l|}{ Laboratory findings } \\
\hline PCR confirmed diagnosis (\%) $n=213$ & $79 \%$ & $75 \%$ & $90 \%$ & 0.023 \\
\hline C-reactive protein $(\mathrm{mg} / \mathrm{L})$ & $\begin{array}{c}101.2 \pm \\
83.6\end{array}$ & $95.9 \pm 83.5$ & $118.0 \pm 82.3$ & 0.05 \\
\hline CRP $<5$ mg/L (\%) & $5 \%$ & $6 \%$ & $1 \%$ & 0.108 \\
\hline $\mathrm{CRP}<100 \mathrm{mg} / \mathrm{L}(\%)$ & $57 \%$ & $60 \%$ & $47 \%$ & 0.051 \\
\hline CRP $100-199$ mg/L (\%) & $28 \%$ & $25 \%$ & $36 \%$ & 0.075 \\
\hline $\mathrm{CRP} \geq 200 \mathrm{mg} / \mathrm{L}(\%)$ & $15 \%$ & $14 \%$ & $17 \%$ & 0.64 \\
\hline Creatinine $(\mu \mathrm{mol} / \mathrm{L})$ & $\begin{array}{c}115.7 \pm \\
110.4\end{array}$ & $\begin{array}{c}103.6 \pm \\
93.2\end{array}$ & $154.6 \pm 147.6$ & 0.001 \\
\hline Creatinine $\geq 133 \mu \mathrm{mol} / \mathrm{L}(\%)$ & $21 \%$ & $17 \%$ & $33 \%$ & 0.003 \\
\hline \multicolumn{5}{|l|}{ Radiologic findings ( $n=250$ ) } \\
\hline $\begin{array}{l}\text { Percentage of lung affected on the CT } \\
\text { scan (\%) }\end{array}$ & $29 \pm 18$ & $28 \pm 17$ & $31 \pm 22$ & 0.253 \\
\hline $\begin{array}{l}\text { Proportion of lung affected on the CT } \\
\text { scan }>50 \%(\%)\end{array}$ & $7 \%$ & $5 \%$ & $14 \%$ & 0.028 \\
\hline Typical CT-scan (\%) & $14 \%$ & $15 \%$ & $7 \%$ & 0.125 \\
\hline Bilateral pulmonary infiltration (\%) & $46 \%$ & $48 \%$ & $36 \%$ & 0.120 \\
\hline Ground-glass opacities (\%) & $29 \%$ & $33 \%$ & $14 \%$ & 0.008 \\
\hline
\end{tabular}

invasion rate $>50 \%$ (average percentage of invasion: $29 \% \pm 18$ ) (Table 2). Among the 306 patients eligible for analysis, 250 had a lung CT scan and 213 a RT-PCR.

\section{Symptoms}

The most common symptoms were dyspnea (67\%), fever (60\%), fatigue $(59 \%)$, cough $(51 \%)$, diarrhea $(30 \%)$, myalgia $(18 \%)$ and dizziness/fall (17\%). Only $6 \%$ of patients reported ageusia/anosmia on admission (Table 2). 


\section{Analysis of Non-survivors as Compared with Survivors}

Tables 1 and 2 show the distribution of demographic characteristics and coexisting conditions among survivors and non-survivors. Nonsurvivors were older $(\mathrm{p}<0.0001)$ and had a greater prevalence of chronic heart disease $(p=0.005)$, cerebrovascular accident $(p=0.002)$, chronic kidney disease ( $\mathrm{p}=0.001)$, and immunodeficiency $(\mathrm{p}<0.0001)$. Among medication, aspirin ( $\mathrm{p}=0.001)$, corticosteroids $(\mathrm{p}=0.008)$, betablockers $(\mathrm{p}=0.007)$ and diuretics $(\mathrm{p}<0.0001)$ were more commonly used by non-survivor patients. The non-survivors were faster hospitalized after the first symptoms ( $4.5 \pm 8.5$ days vs. $7.2 \pm 7.5$ days $)$. Among non-survivors mortality rate was of $25 \%$ and transfer to ICU was of $3 \%$. Laboratory and radiologic findings for non-survivors reveal fewer signs at admission of renal dysfunction (creatinine $\geq 133 \mu \mathrm{mol} / \mathrm{L}$; $\mathrm{p}<0.003)$ and lung invasion rate $(>50 \% ; \mathrm{p}<0.028)$. The multivariate analysis of factors associated with non-survival reveals that increasing age was a strong predictor of in hospital mortality after adjusting for major comorbidity (per additional year, OR 1.083; p=0.003) (Figure 1). Stroke history (OR: 2.983; $\mathrm{p}=0.027$ ), immunodeficiency (OR:4.665; $\mathrm{p}=0.002$ ) and percentage of the lung affected on the CT scan were also statistically associated with increased hospital mortality (OR:1.032 per additional percent of lung affected; $\mathrm{p}=0.009$ ). The other factors don't show a significant implication on the patient outcomes.

\section{Antiviral Treatment}

Fifty-three patients received the HCQ/AZI association, 13 the lopinavir/ritonavir association, 12 azithromycin alone and 5 HCQ alone. The HCQ/AZI have been administered an average of $7.9 \pm 3.1$ days of treatment. Among 16 patients who did not receive the 10 days of treatment, the causes were: transfer to ICU $(\mathrm{N}=6)$, widening of the QTc wave ( $\mathrm{N}=6$; occurring between 1 and 8 days after initiation of treatment), renal failure $(\mathrm{N}=1)$, death $(\mathrm{N}=2$; after 1 and 3 days of treatment), pseudo-cerebellar syndrome attributed to viral damage combined with HCQ $(\mathrm{N}=1)$. The patients treated by HCQ/AZI had severe form of COVID-19 (9\% of lung affected on CT-scan), were younger patient (13 years) and tend to have more comorbidities except diabetes and immunodeficiency. Percentage of lung affected on CTscan was the only variable statistically associated with death or ICU transfer (OR:1.033 [1.002-1.064], p=0.039) among patients admitted into the two internal medicine ward where HCQ-AZI were used. The sub-study ( $\mathrm{N}=96)$ which evaluate the efficacy of treatment with HCQ/AZI for the patients admitted into the two internal medicine units included 96 patients. There was no significant difference in demographic, comorbidities, smoking status, home drug treatment and laboratory/radiologic findings between the treated and untreated population. If the mortality of patients treated with HCQ/AZI seems different, this result is not statistically significant $(0 \%$ vs. $8 \%$; $\mathrm{p}=0.122)$.

\section{Discussion}

The COVID-19 situation worldwide, as of 1 July 2020 based on the data transmitted by the different countries is 10446353 cases of COVID-19 including 511037 deaths [1]. If the number of new cases seems to decrease in Europe, the world wide situation continues to worsen. The average incubation period for COVID-19 is 5 days [3]. The interval from symptom onset the hospital admission is 6 , days in our study. The average age of patients in our study (75.6 years) is higher than the studies currently published (47-73 years) with a male preponderance 3 . The clinical manifestation of COVID-19 is various. We found standard symptoms in hospitalized patients included: dyspnea, fever, asthenia, cough, diarrhea, muscle ach and dizziness/ fall. Anosmia ageusia may be identified in only $6 \%$ of patients. If comorbidities presented by $89 \%$ of our patients are among the most common (hypertension, diabetes mellitus), they are present in a remarkably high rate of our patients (chronic heart disease $>70 \%$, chronic kidney disease $>25 \%$, immunodeficiency $>20 \%$ ) [4,5]. Obesity seems to play a special role affecting more than $25 \%$ of our patients. Obesity or excess ectopic fat deposition are suspected of unifying

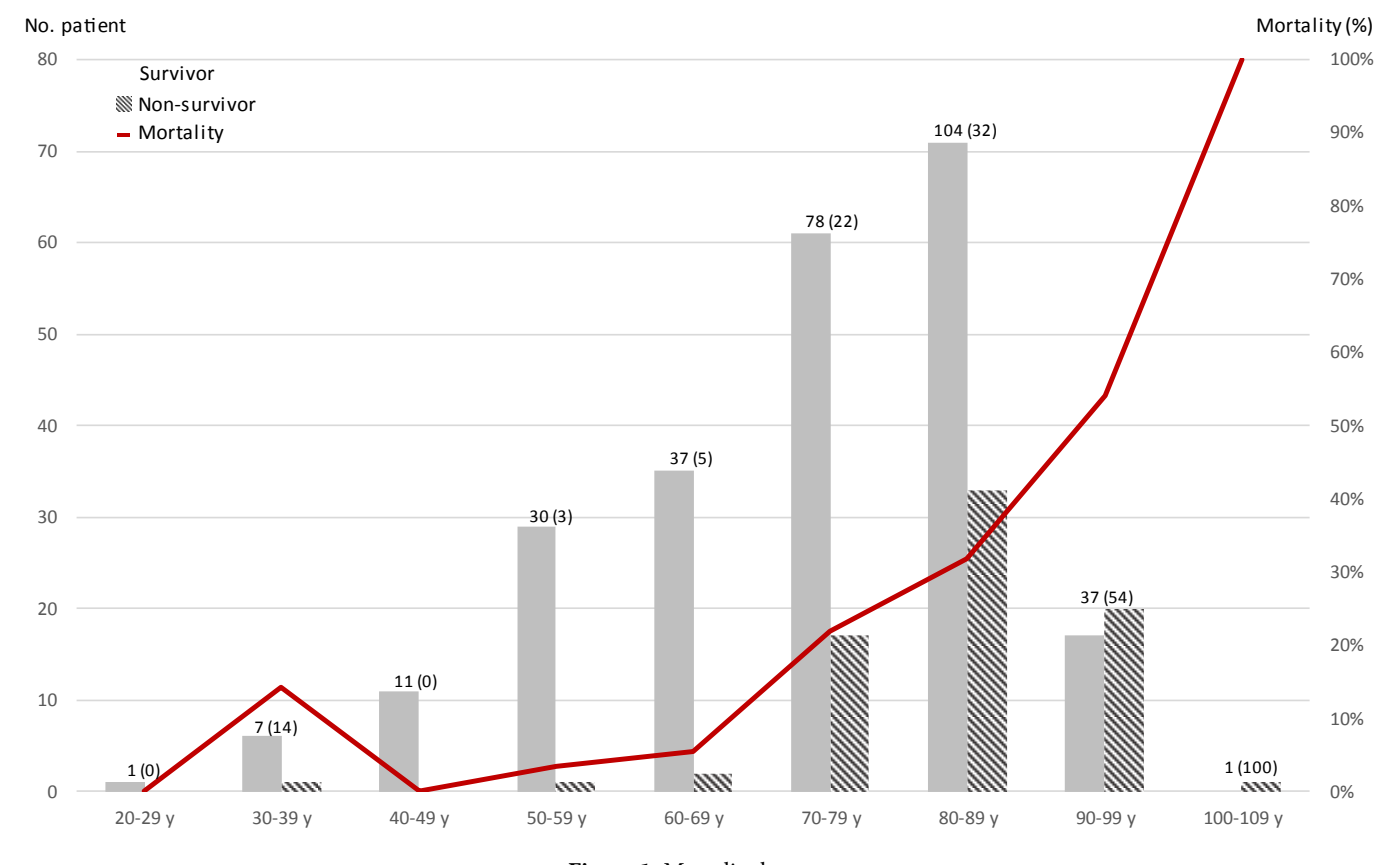

Figure 1: Mortality by age. 
risk factor for severe COVID-19 infection, reducing both protective cardiorespiratory reserve as well as potentiating the immune dysregulation that appears, at least in part, to mediate the progression to critical illness and organ failure in a proportion of COVID-19 patients [6]. However, it should be noted that it does not appear as a factor of death. Concerning the long-term treatments taken by the patient, the patients treated with aspirin, diuretics, betablockers or corticoids are significantly higher in the non-survivor group. But, it is difficult to attribute excess mortality to these treatments, since they are generally used to manage the comorbidity previously mentioned. The search for a predictive sign of worsening of a patient's condition at admission is a major issue in medical management. There is an excess mortality in patients more older (Figure 1), patients who on admission have dyspnea, oxygen saturation $\leq 93 \%$, a lung invasion rate $>50 \%$ or a creatinine $>133 \mu \mathrm{mol} / \mathrm{L}$. These elements are warning signs for the physician supported by other publications on the subject [7]. On the other hand, on the advanced side on antiviral treatment, there has been no notable progress to date. Among the treatments discussed, remdesivir, the ritonavir/lopinavir and HCQ/AZI combination were the first treatments offered in France. For reasons essentially of availability, hydroxychloroquine associated or not with azithromycin has become one of the only therapeutic options in the absence of any evidence of effectiveness. Gautret et al. published the first result of the HCQ/AZI efficiency in COVID-19 patients [8]. They demonstrated on a series of 80 patients an undetectability of viral load at the nasopharyngeal level in $83 \%$ of patients on day $7,93 \%$ on day 8 [9]. Respiratory samples are negative in $97.5 \%$ of patients on day 5 . However, patients in this study had a low rate of comorbidity for an average age of 52.5 years. They do not appear to be the most at risk of complications given the current state of knowledge. Thus, only $53.8 \%$ $(43 / 80)$ had a CT-scanner lung disease and 15\% (12/80) had oxygen need. This population appears to have a relatively mild impairment compared to our study population. In agreement with the relative viral RNA load reduction, in vitro tests show a cytopathic effect of SARSCoV 2 could be observed in only $16 \%(5 / 31)$ wells at $60 \mathrm{~h}$ post infection after HCQ/AZI exposition as compared to $100 \%(13 / 13)$ in positive controls [9]. Rosenberg et al. publish an observational study to report adverse events and mortality of HCQ and/or azithromycin among patients with COVID-19 (Number of patient: 735 with HCQ/AZI, 271 with HCQ, 211 with azithromycin, 221 any treatment - similar age: 61.4 to 65.5 average) [10]. Cardiac arrest was more frequent in patients who received HCQ with azithromycin, compared with patients who received neither drug, even after adjustment. Moreover, treatment with HCQ, azithromycin, or both, compared with neither treatment, was not significantly associated with differences in inhospital mortality. Mahevas et al report a study carried out on 181 patients requiring oxygen therapy excluding patients transferred to ICU [11]. In their study, 15 patients were treated with the HCQ/AZI combination, none were transferred to ICU and none died.

The treatment of patients was done according to modalities (collegial doctor's decision) and within deadlines close to ours (7 days after the onset of symptoms). The mortality reported in this study is lower than ours. This can be attributed to the exclusion of patients without ICU need and the average age of the population (60 years vs.
75 years), even if the predictors of aggravation are relatively similar (CRP, percentage of pulmonary invasion). Interestingly, the authors put into perspective the importance of treatment with an antiviral during the virus contamination phase. However, HCQ exhibits immunomodulatory properties through its action on interleukin 1, 2 and $6, \mathrm{TNF} \alpha$ and the inhibition of toll-like receptors. This explains its effectiveness in certain autoimmune pathologies which in the case of the inflammatory storm identified in certain forms of COVID-19 could be of theoretical interest. Nevertheless, the latest published clinical data, consistent with our series, point out that during the inflammatory phase (usually on the second week of symptoms) this treatment should have any effectiveness. Side effects, particularly of the heart, in patients with fragility induced by viral infection remain a warning point for physician using the HCQ/AZI combination. In our cohort of treated patients $11.3 \%$ (6/53) had heart rhythm problems. As rhythm disturbances were not systematically sought in the untreated group, it is difficult to conclude on an increase in disorders due to COVID-19 disease or to antiviral treatment. A study of 201 patients demonstrated that Baseline QTc intervals did not differ between patients treated with chloroquine/HCQ (monotherapy group) vs. those treated with combination group (chloroquine/HCQ and azithromycin) $(440.6 \pm 24.9 \mathrm{~ms}$ vs. $439.9 \pm 24.7 \mathrm{~ms}, \mathrm{p}=0.834)$ [12]. More recently Mehra et al. presented a multinational registry analysis carried out on the largest population studied to date (96 032 patients; mean age $53.6 \pm 17.6$; oxygen saturation $<94 \%$; $19.9 \%$ of nonsurvivors patient) [13]. This article which seemed to make everyone agree was retracted a few days after its publication by its authors. However we should note that the authors reported an excess mortality in patients treated with combination of HCQ (main dosage $587 \mathrm{mg}$ $\pm 128 \mathrm{mg}$ during $4.3 \pm 2.0$ days) with a macrolide (azithromycin or clarithromycin; dosage not communicated) as well as a de-novo ventricular arrhythmia in $8.1 \%$ of patients treated (versus $0.3 \%$ of untreated patients). We find a similar percentage of ventricular rhythm disorders (11.3\% vs. $8.1 \%)$ in our patients with a more advanced age (75 years vs. 54 years), a comorbidity rate, predictors of severity and duration longer treatment (7.9 vs. 4.3 days). However, we did not find an increase in the mortality of patients treated with the HCQ/AZI combination. In view of these various elements, it remains necessary to remain cautious. The need for QT interval monitoring remains necessary. We draw attention to the difficulty to interpret the results of a non-randomized observational study. Indeed, in the absence of randomization, the mortality comparison data in the group treated by HCQ/AZI and the group not treated are impacted by many biases. Thus, if mortality seems different in the total study population (HCQ/ AZI: $6 \%$ vs. Other: $28 \%$ ) and in the sub-study population (HCQ/ AZI: $0 \%$ vs. Other $8 \%$ ), it is distorted by populations that are not comparable (age, risk factor) and different treatment methods desired or not by physicians. We no longer observe any significant difference after identifying and taking into account the biases inherent in this type of study. As a conclusion, the question of the efficiency and safety of the HCQ/AZI combination in the treatment of COVID-19 disease remains open pending the results of randomized clinical studies (Figure 1 and Tables 1-3). 
Maloisel Frédéric (2020) Observational Study of the Effect of the Hydroxychloroquine/Azithromycin Combination in Patients Hospitalized for a Severe Form of COVID-19

Table 3: Multivariate analysis of factors associated with death.

\begin{tabular}{|c|c|c|}
\hline Demographic data & Adjusted OR (CI 95\%) & p-value ${ }^{* *}$ \\
\hline Age - yr & $1.083(1.028-1.142)$ & 0.003 \\
\hline Sex (male sex) & $0.52(0.216-1.25)$ & 0.144 \\
\hline Body mass index $\left(\mathrm{kg} / \mathrm{m}^{2}\right)$ & $0.971(0.886-1.063)$ & 0.518 \\
\hline Nursing home resident & $1.758(0.457-6.757)$ & 0.411 \\
\hline \multicolumn{3}{|l|}{ Comorbidities } \\
\hline Hypertension & $1.923(0.758-4.881)$ & 0.169 \\
\hline Diabetes mellitus & $0.566(0.201-1.591)$ & 0.281 \\
\hline Chronic heart disease & $1.032(0.34-3.129)$ & 0.955 \\
\hline Chronic respiratory disease & $0.759(0.274-2.103)$ & 0.595 \\
\hline Dialysis & $2.045(0.295-14.149)$ & 0.469 \\
\hline Immunodeficiency & $4.665(1.73-12.58)$ & 0.002 \\
\hline Cerebrovascular accident & $2.983(1.13-7.875)$ & 0.027 \\
\hline \multicolumn{3}{|l|}{ Smoking status } \\
\hline Current smoker & $3.564(0.31-40.92)$ & 0.307 \\
\hline Former smoker & $1.448(0.389-5.393)$ & 0.581 \\
\hline \multicolumn{3}{|l|}{ Symptoms at onset of illness } \\
\hline Dyspnea & $1.332(0.521-3.406)$ & 0.549 \\
\hline Hypoxemia (oxygen saturation < $93 \%$ ) & $0.936(0.383-2.284)$ & 0.884 \\
\hline \multicolumn{3}{|l|}{ Laboratory findings } \\
\hline Creatinine $(\mu \mathrm{mol} / \mathrm{L})$ & $1.002(0.999-1.006)$ & 0.182 \\
\hline \multicolumn{3}{|l|}{ Radiologic findings } \\
\hline Percentage of lung affected on the CT scan (\%) & $1.032(1.008-1.057)$ & 0.009 \\
\hline
\end{tabular}

\section{Conflict of Interest}

The authors declare they have no conflict of interest.

\section{Ethics Approval}

The study has been approved by the ethics committee of the Groupe Hospitalier Saint Vincent (GRE 2020-01). Written informed consent has been waived in light of the urgent need to collect clinical data.

\section{References}

1. https://www.ecdc.europa.eu/en/geographical-distribution-2019-ncov-cases. Consulted on 2020/07/28.

2. https://apps.who.int/iris/bitstream/handle/10665/332437/WHO-2019-nCoVclinical-2020.5-fre.pdf Consulted on 2020/07/28.

3. Wiersinga WJ, Rhodes A, Cheng AC, Sharon J P, Hallie C P (2020) Pathophysiology. Transmission. Diagnosis. and Treatment of Coronavirus Disease 2019 (COVID-19): A Review. JAMA. [crossref]

4. Zhou F, Yu T, Du R, Guohui F, Ying L, (2020) Clinical course and risk factors for mortality of adult inpatients with COVID-19 in Wuhan. China: a retrospective cohort study Lancet 395.

5. Petrilli CM, Jones SA, Yang J, Rajagopalan H, Luke O'Donnell, et al. (2020) Factors associated with hospital admission and critical illness among 5279 people with coronavirus disease 2019 in New York City: prospective cohort study. BMJ. [crossref]

6. Yang J, Hu J, Zhu C (2020) Obesity aggravates COVID-19: a systematic review and meta-analysis. J Med Virol.

7. Wynants L, Van Calster B, Collins GS, Richard D Riley, Georg Heinze, et al. (2020) Prediction models for diagnosis and prognosis of covid-19 infection: systematic review and critical appraisal. $B M J$ [crossref]

8. Gautret P, Lagier JC, Parola P, Van Thuan Hoang, Line Meddeb, et al. (2020) Clinical and microbiological effect of a combination of hydroxychloroquine and azithromycin in 80 COVID-19 patients with at least a six-day follow up: A pilot observational study. Travel Med Infect Dis. [crossref]

9. Andreani J, Le Bideau Mm, Duflot I, Priscilla Jardot, Clara Rolland, et al. (2020) In vitro testing of combined hydroxychloroquine and azithromycin on SARS-CoV-2 shows synergistic effect. Microb Pathog. [crossref]

10. Rosenberg ES, Dufort EM, Udo T, Larissa A, Wilberschied, Jessica Kumar, et al. (2020) Association of Treatment With Hydroxychloroquine or Azithromycin With In-Hospital Mortality in Patients With COVID-19 in New York State. JAMA 323 : 2493-2502. [crossref]

11. Mahévas M, Tran VT, Roumier M, Amélie Chabrol, Romain Paule, et al. (2020) Clinical efficacy of hydroxychloroquine in patients with covid-19 pneumonia who require oxygen: observational comparative study using routine care data. BMJ 369. [crossref]

12. Saleh M, Gabriels J, Chang D, Beom SK, Amtul Mansoor, et al. (2020) The Effect of Chloroquine. Hydroxychloroquine and Azithromycin on the Corrected QT Interval in Patients with SARS-CoV-2 Infection. Circ Arrhythm Electrophysiol. [crossref]

13. Mehra MR, Desai SS, Ruschitzka F, Amit N Patel (2020) Hydroxychloroquine or chloroquine with or without a macrolide for treatment of COVID-19: a multinational registry analysis. Lancet.

\section{Citation:}

Santucci Raoul, Vinzio Stéphane, Brisson Jihane, Caille Cécile, Geiger Audrey, et al. (2020) Observational Study of the Effect of the Hydroxychloroquine/Azithromycin Combination in Patients Hospitalized for a Severe Form of COVID-19. J Pharmacol Pharm Res Volume 3(2): 1-6. 